\title{
Special Twin Environments, Genetic Influences and their Effects on the Handedness of Twins and their Siblings
}

\author{
Sarah E. Medland', 2, Margaret J. Wright', Gina M. Geffen², David A. Hay ${ }^{3}$, Florence Levy4, \\ Nicholas G. Martin', and David L. Duffy' \\ ' Queensland Institute of Medical Research, Australia \\ ${ }^{2}$ Cognitive Psychophysiology Laboratory, University of Queensland, Australia \\ ${ }^{3}$ Department of Psychology, Curtin University of Technology, Australia \\ ${ }^{4}$ School of Psychiatry, University of New South Wales, Australia
}

\begin{abstract}
t has been suggested that twinning may influence handedness through the effects of birth order, intra-uterine crowding and mirror imaging. The influence of these effects on handedness (for writing and throwing) was examined in 3657 Monozygotic (MZ) and 3762 Dizygotic (DZ) twin pairs (born 1893-1992). Maximum likelihood analyses revealed no effects of birth order on the incidence of left-handedness. Twins were no more likely to be left-handed than their singleton siblings ( $n=1757$ ), and there were no differences between the DZ co-twin and siblingtwin covariances, suggesting that neither intra-uterine crowding nor the experience of being a twin affects handedness. There was no evidence of mirror imaging; the co-twin correlations of monochorionic and dichorionic MZ twins did not differ. Univariate genetic analyses revealed common environmental factors to be the most parsimonious explanation of familial aggregation for the writing-hand measure, while additive genetic influences provided a better interpretation of the throwing hand data.
\end{abstract}

Although numerous theories have been proposed, the determinants of human handedness remain unknown. Evidence that the development of handedness begins prenatally comes from ultrasound studies which have found that behavioral laterality is first demonstrated at between 9 and 10 weeks gestational age as embryos begin to exhibit single arm movements (Hepper et al., 1998). At 10 weeks gestational age, $75 \%$ of the 72 fetuses showed more right than left arm movements with the remainder showing either a left arm preference $(12.5 \%)$ or no difference in the number of left, right movements (12.5\%). Similarly, in a longitudinal study of preferential thumb sucking (which correlates with childhood handedness; (McManus, 2002) from 15 weeks gestational to term, Hepper and colleagues (1998) found a bias towards right thumb sucking that was maintained throughout pregnancy.

While there is little doubt that pathogenic and environmental influences can alter an individual's handedness (James \& Orlebeke, 2002), the origin of the population bias toward right handedness remains obscure. The two most popular genetic theories in the literature at present are the Right shift (RS; Annett, 1985) and Dextral Chance (D/C; McManus, 1985) theories of handedness which both propose a single major gene influencing handedness.
Both the RS and D/C theories propose models in which one allele results in a bias towards right handedness (the RS+/D allele respectively), while the second allele (the RS-/C allele) results in an individual's handedness developing without a biological bias leading to a $50 \%$ chance of left-handedness. Although, Annett has stated that environmental factors may act to reduce the effect of the RS- allele resulting in 34\% and $8 \%$ left-handedness in RS- homozygous and heterozygous individuals respectively (Annett, 1996).

The hypothesis that handedness is genetically determined has received mixed support. Neale's (1986) analysis of self-reported handedness in 1687 twin pairs yielded low estimates of heritability $(-20 \%)$ and the effects of shared environment $(-7 \%)$. Despite the size of the sample, Neale was unable to distinguish between models in which the variance and/or liability of left-handedness differed between males and females (the prevalence of left-handedness for males was $14.1 \%, 12.3 \%$ for females) leading to the conclusion that non-shared environmental factors were responsible for the majority of the variance in hand preference. A recent genomewide linkage screen for relative hand skill (as measured by the Annett (1985) peg board task) found evidence of a quantitative trait loci (QTL) on chromosome 2p11.2-12 in a sample of 195 sib-pairs (Francks et al., 2002). This result was not replicated in an analysis of the 2p11.1-12 locus in a second sample of sib-pairs leading Francks et al. to conclude that hand skill, "is a complex phenotype with a multifactorial background that includes heterogenous environmental and/or genetic influences" (p. 804). Linkage of relative hand skill to 2p12-q11 has recently been confirmed in a third sample (Francks et al., 2003). Segregation analysis of an informative extended pedigree by Van Agtmael et al. identified two candidate regions (NODAL on chromosome 10 and DNAHC13 on chromosome 1). However, subsequent non-parametric linkage analysis on nuclear families excluded these candidate regions (Van Agtmael et al., 2002).

Address for correspondence: Sarah Medland, Genetic Epidemiology Unit, Queensland Institute of Medical Research, 300 Herston Rd, Brisbane, Queensland 4029, Australia.Email: sarahMe@qimr.edu.au 
Between 10 to $25 \%$ of $\mathrm{MZ}$ twins are discordant for handedness (Reiss et al., 1999; Ross et al., 1999; Sicotte et al., 1999). While both the RS and D/C models can explain discordant handedness in $\mathrm{MZ}$ twin pairs, both models still predict greater concordance in $\mathrm{MZ}$ than $\mathrm{DZ}$ twins. Recurrence Risks (when the prevalence of $\mathrm{LH}$ in the sample is $10 \%$ ) for $\mathrm{MZ}$ and $\mathrm{DZ}$ twins are predicted to be $23.3 \%$ and $16.4 \%$ under the RS model, and $30 \%$ and $20 \%$ under the D/C model (calculated using SIB-PAIR; Duffy, 2002). However, the majority of studies examining handedness in twins find no difference between the concordance rates of $\mathrm{MZ}$ and $\mathrm{DZ}$ twins.

Thus, either the influence of genetic factors on handedness is smaller than that predicted by the RS and D/C theories, as suggested by Neale (1986), or alternatively, the rate of discordance in $\mathrm{MZ}$ twin pairs is being influenced by a confounding factor that is acting to decrease the ability to generalize models of handedness etiology developed in singleton populations to data collected in twins. Previous research has suggested that environmental influences relating to twinning might play such a role in influencing the handedness of twins. The purpose of the present study is to examine the influence of these effects in a large sample of Australian twins.

\section{Does the Experience of Twinning Affect Handedness?}

Meta-analysis has found that twins show increased rates of left-handedness compared to singletons, although this finding is less common in more recent studies (Sicotte et al., 1999). Increased left-handedness in twins is usually attributed to an increase in prenatal and birth-related complications, and low birthweight among twins when compared to singletons (Sicotte et al., 1999) or to sub optimal in utero conditions (Rife, 1940).

\section{Birth Order}

Studies of singletons have found an increased prevalence of left-handers among very low birthweight children (Powls et al., 1996) and those who have experienced high levels of birth stress (Coren \& Halpern, 1991). However, there is evidence that in general, the long-term effects of low birthweight in twins may differ from those seen in singletons (Phillips et al., 2001). While the first-born twin is less likely to experience neo- and peri-natal complications (Voss, 1996) and more likely to be heavier (Orlebeke et al., 1993) than the after-coming twin, studies have found that the first-born twin was more likely to be left-handed than the second-born (Christian et al., 1979; Orlebeke et al., 1996). Orlebeke et al. suggest that this birth order effect is more extreme when the first-born twin weighs less than the second-born twin. However, a reanalysis of this data, concluded that the "association (between handedness and birthweight) is weaker in handedness-discordant twins [than in singletons] (apparently as a consequence of the opposing and more powerful influence of birth order)", and that first-born twins may experience a "greater risk of physical trauma" suggesting "that trauma is a more important determinant of left-handedness than hypoxia" (James \& Orlebeke, 2002, p. 305). This suggestion is problematic as it suggests that handedness may be affected by fairly innocuous physical and neurological insults and the considerable plasticity of the central nervous system at birth is either insufficient to repair the damage or that there is no selective advantage in doing so. An alternative explanation may be that some of these twins might not have developed a pre-natal preference for use of one hand over the other, and thus may be more susceptible to birth and early environmental stresses. However, this would not account for the apparent increase in left-handedness in first-born twins.

\section{Intra-uterine Crowding}

The hypothesis that handedness in twins might be influenced by intra-uterine crowding was raised by Rife (1940) in an attempt to explain why the prevalence of handedness in his sample of 369 twin pairs was significantly higher $(13.3 \%)$ than that seen in the singleton sample $(7.5 \%)$. However, as Carter-Saltzman et al. (1976) point out the data required to effectively evaluate the veracity of this hypothesis (degree and duration of rotation and shifting, size of the mother, birthweight of twins etc.) need to be considered objectively. Comparing the prevalence of left-handedness in twins with that of their non-twin siblings allows one to examine firstly whether the experience of being a twin (including, the sharing of limited space and resources, and the differences in the birth process) is associated with an increased risk of left-handedness. Similarly, comparing the DZ co-twin correlation with twin-sib correlations allows an examination of the role of pre or peri-natal interaction between the twins that might influence handedness. One of the advantages of comparing twins with their non-twin siblings is that by using siblings as the control group we can, at least in part, control for variance in maternal size and the effects of genetic transmission (as both DZ twins and their full siblings share, on average, $50 \%$ of their genetic material).

\section{Does the Process of MZ Twinning Affect Handedness?}

The theory of mirror imaged handedness (Newman, 1928) proposes a mechanism which acts to increase the rate of discordance within MZ twin pairs and increase the rate of left-handedness across $M Z$ twins. Based on studies examining the shell-markings of armadillos, Newman proposed that in later-splitting embryos where $\mathrm{MZ}$ twinning occurs after lateralization has been established in the blastocyst, the cotwins will show discordant handedness and a range of other heterotaxic or mirrored physical characteristics. Twin pairs with mirrored features (also known as chiral or enantiomer twins) are in effect, incongruent counterparts of each other, in the same way that (in most people) the left hand is an incongruent counterpart of the right (McManus, 2002).

Mirrored features in chiral twins are restricted to those of ectodermal derivative (McManus, 1980), suggesting that the timing of lateralization, and period of plasticity in which lateralization may be altered, may be tissue specific (Levin, 1999). The hypothesis that handedness may be influenced by mirror imaging originates from the belief that handedness is causally related to cerebral lateralization of language functions (Newman, 1928). However, while left-handers are more likely to show right hemisphere language lateralization than right handers (30\% vs. $5 \%)$, the majority of both left and right handers have language lateralized in the left hemisphere and the majority of individuals with right hemisphere language lateralization are right handers (Bryden et al., 
1997). Similarly, in fRMI studies of MZ twin pairs discordant for handedness (Sommer et al., 2001; Sommer et al., 1999), the proportion of left-handers showing right hemisphere language lateralization is identical to that seen in left-handed singletons (Pujol et al., 1999).

Recent empirical studies (Chitnis et al., 1999; Monterio et al., 1998; Trejo et al., 1994) have supported the long held belief that the earliest splitting twins are MZ dichorionic (DC) $(-33 \%$ of $M Z$ twins) twins who have separate amnions and separate or fused placentas followed by $\mathrm{MZ}$ monochorionic (MC) twins $(-67 \%)$ who have separate (diamniotic, DA: -63\%) or shared amnions (monoamniotic, MA: $-4 \%$ ) and a shared placenta (Bulmer, 1970; Derom et al., 1995). Thus, if the theory of mirror imaging were correct the highest incidence of chiral twining should be seen in MA-MC twins followed by DA-MC twins and MZ DC twins. However, while mirror imaging has been discussed in the literature for almost a century, the issue of whether mirroring is more common in $\mathrm{MZ} \mathrm{MC}$ than $\mathrm{MZ}$ DC twin pairs has received little empirical attention. The difficulty in determining whether mirroring is more frequent in $\mathrm{MC}$ than DC twin pairs may be due in part to the problem of distinguishing MC from DC placentas as $-40 \%$ of DC placentas fuse and may be mistaken for MC placentas. Thus, the number of placentas may not be a reliable indicator of chorionicity.

Although early studies of handedness in twins supported the theory of mirror imaging (Raney, 1938; Rife, 1933; Roman-Goldzieher, 1945), the results of more recent studies do not. It is possible that the early support of this theory may be confounded by the inaccuracy of zygosity determination as, "some investigators felt that discordant handedness was a marker of zygosity” (Sicotte et al., 1999, p. 282). The unqualified acceptance of early research has lead to circularity in the literature and the use of retrospective estimation of chorionicity in some studies. For example, Davis and Phelps (Davis \& Phelps, 1995), who assessed the relationship between chorionicity and concordance for schizophrenia in $\mathrm{MZ}$ twin pairs used handedness concordance as a retrospective marker of placentation, while Newman (1928) used degree of physical similarity to distinguish early splitting twins from late splitting twin pairs. It is also possible that other factors, such as twin-twin transfusion syndrome (which occurs more commonly in MZ MC than MZ DC twins) may be responsible for some of the previous findings of increased discordance in some MZ twin samples (Hay \& Howie, 1980). Reviews of the literature examining handedness in twins by McManus (1980) and Sicotte, Woods and Mazziotta (1999) found no support for the theory of mirror imaging. Similarly, studies that have examined the relationship between handedness and chorionicity have found no difference in hand preference (Derom et al., 1996), or hand skill (Carlier et al., 1996), between MZ MC and MZ DC twins.

\section{Hypotheses}

Using data from several completed and on-going studies, a series of maximum likelihood analyses were conducted to test the following hypotheses. Based on the results of previous studies, if the experience of being a twin were influencing the handedness in our sample we might expect to find: 1) a higher prevalence of left-handedness in twins than in singletons, 2) a birth order effect, and 3) a difference between DZ co-twin correlations and the twin-sibling or sibling-sibling correlations. If the process of $\mathrm{MZ}$ twinning were affecting the handedness of $M Z$ twins we might expect to find: 1) a higher prevalence of left-handedness and lower co-twin correlations in $\mathrm{MZ} \mathrm{MC} \mathrm{twins} \mathrm{as} \mathrm{compared} \mathrm{to} \mathrm{MZ}$ DC twins, and 2) a higher prevalence of left-handedness in $\mathrm{MZ}$ twins as compared to $\mathrm{DZ}$ twins.

\section{Materials and Methods \\ Participants}

The data considered in these analyses were collected in four different studies (Duffy et al., 1998; Kirk et al., 2000; Levy et al., 1996; Wright et al., 2001). Information regarding the foci of these studies, their selection criteria, protocols and methodologies are summarized in Table 1 below. Information on sample size and age range is given in Table 2. Sibling data were collected during both the MAPS and ADHD studies. In the ADHD study data from up to two siblings (the two who were closest in age to the twins) were collected. In the MAPS study up to two siblings also participated. Sibling information was available for 1370 of the 7266 families in the analysis (a total of 1757 siblings, mean year of birth $=1982$, range 1969-1992). The sibling data were included in the present analyses to provide information about possible differences in handedness between twins and singletons and the generalizability of these results to singleton populations.

Both the asthma study (Duffy et al., 1998) and the sexuality study (Kirk et al., 2000) recruited participants from the same two twin cohorts born 1893-1964, and 1965-1971. While the sexuality study was constructed to maintain respondent anonymity, participants in the sexuality study returned a consent form in a separate envelope. Thus to avoid inclusion of duplicate data, all individuals who returned a consent form from the sexuality study were excluded from the asthma study data set. This procedure resulted in the exclusion of 324 twin pairs and 153 individual twins, resulting in the substantial individual attrition rates shown in Table 2.

Similarly, a small number of twin pairs (47) participated in both the ADHD study (Levy et al., 1996) and the MAPS study (Wright et al., 2001) and data from these participants were included in the MAPS data set (in which the data were self reported) and excluded from the ADHD set (in which the data were reported by the twins' parents). As reported below, the duplicate data were used to estimate the validity and reliability of our measures. The relatively small overlap between these two studies is due to sampling differences, with the ADHD study drawing participants from the Australian Twin Registry, while in the MAPS study twins were recruited directly from schools in SouthEast Queensland.

\section{Measures}

\section{Handedness}

This paper considers two indices of handedness based on the two items which were common to all four studies; a) which hand would you use to write a letter? (in the ADHD study parents were asked for hand used for drawing), and b) which hand would you use to throw a ball to hit a target? In all 
Table 1

A brief Overview of the Focus and Methodology of the Four Studies in which the Data were Collected

\begin{tabular}{|c|c|c|c|c|c|}
\hline \multirow[t]{2}{*}{ Study \& Focus } & \multirow[t]{2}{*}{ Selection } & \multirow[t]{2}{*}{ Protocol type } & \multicolumn{3}{|c|}{ Method used to determine: } \\
\hline & & & Handedness & Placentation & Zygosity \\
\hline $\begin{array}{l}\text { Duffy et al. } 1998 \\
\text { Asthma } \\
\text { and Atopy }\end{array}$ & $\begin{array}{l}\text { At least } 1 \\
\text { co-twin } \\
\text { had reported } \\
\text { Asthma } \\
\text { or wheezing }\end{array}$ & Questionnaire & Self-report & $\begin{array}{l}\text { Parental report from } \\
\text { previous studies was } \\
\text { used where available. } \\
\text { Self-report was used } \\
\text { if parental report was } \\
\text { unavailable. When } \\
\text { co-twins reported } \\
\text { different numbers of } \\
\text { placentas the pair } \\
\text { was classified as } \\
\text { "placentation unknown" }\end{array}$ & $\begin{array}{l}\text { Twins responses } \\
\text { to standard } \\
\text { questions about } \\
\text { similarity and the } \\
\text { degree to which } \\
\text { others confuse } \\
\text { them* For all } \\
\text { same sex twins: } \\
\text { ABO, MN and Rh } \\
\text { Blood Groups. } \\
\text { Nine independent } \\
\text { polymorphic } \\
\text { DNA markers }\end{array}$ \\
\hline
\end{tabular}

$\begin{array}{ll}\text { Kirk et al. } & \text { Participants had } \\ 2000 & \text { indicated they } \\ & \text { would be willing } \\ \text { to participate } & \text { during a previous } \\ \text { study }\end{array}$

Sexual

Orientation

Levy et al.

1996

Behavioural

disorders of

childhood

(ADHD)

Wright
et al.
2001

Memory,

attention

\& problem

solving

(MAPS)

(and thed 4-12

Australian Twin

registry.

\begin{abstract}
Anonymous
questions.

Respondents

were asked to

create a 10 digit

ID number with

their co-twin to

allow matching
\end{abstract}

Questionnaire

registered with the

Note: *

3-4 hour

testing session

measuring: I0,

information

processing,

ERPs during

a working

memory task

\& resting EEG

$\begin{array}{ll}\text { Self-report } & \text { Self-report. } \\ & \text { When co-twins } \\ & \text { reported different } \\ & \text { numbers of placentas } \\ \text { the pair was classified } & \text { as "placentation } \\ \text { unknown" }\end{array}$

Self-report

Hand used to

complete the

working memory

task

Parental Report

Parental Report

Zygosity had been

determined using

the above

methods during a

previous study

(DNA information

was available

for 456 twin pairs).

This information

was pre-printed

on the questionnaire

booklet.

Parents

responses to

standard

questions about

the twins

similarity and the

degree to which

others confuse

the twin

For all same sex

twins: ABO,

$\mathrm{MN}$ and Rh

Blood Groups.

Nine independent polymorphic DNA markers \& * Such procedures
\& Hayakawa, 1990).

studies the respondents were offered three responses: left, right or either. The small number of participants who reported writing or throwing with either hand were treated as left-handers (frequencies of participants reporting either hand for writing and throwing were .7 and $3.9 \%$ respectively). The percentage of twins concordant and discordant for left-handedness, percentage of incomplete twin pairs, prevalence of left-handedness, for both the writing and throwing measures are given in Table 2.

The validity of parental handedness reports was assessed by comparing parental- and self-reported handedness for the 47 pairs of twins who participated in both the MAPS (self-reported handedness) and ADHD studies (parental reported handedness). Parental and self-reported handedness showed high correlations (calculated using PRELIS 8.2), suggesting that parental reports can be considered accurate (writing hand: $r=.97$, throwing hand: $r=.82$ ). Ideally, orthographic observational data would be used to validate the questionnaire data. The hand used to perform a Delayed Response Task, in which participants were required to use a "pen-like pointer" to indicate the location of a remembered object on a computer screen, was recorded for the MAPS sample. As participants received a monetary reward for speed and accuracy it is likely that they used their dominant hand 


\section{Table 2}

The Number of Twin Pairs, Mean Year of Birth (YOB) by Zygosity and Placentation for the Individual Studies and the Combined Sample. Also Given for the Complete Sample (for both the Writing and Throwing Measures) are the Percentage of Incomplete Twin Pairs, Percentage of Twins Concordant and Discordant for Left Handedness, Prevalence of Left Handedness

\begin{tabular}{|c|c|c|c|c|c|c|c|c|c|}
\hline \multirow[t]{3}{*}{ Study } & & \multicolumn{5}{|c|}{ Zygosity } & & \multicolumn{2}{|c|}{ Placentation } \\
\hline & & \multicolumn{2}{|c|}{$\mathrm{MZ}$} & \multicolumn{4}{|c|}{$\mathrm{DZ}$} & \multicolumn{2}{|r|}{$\mathrm{MZ}$} \\
\hline & & Female & Male & Female & Male & OS* & Singles** & MC & $\mathrm{DC}$ \\
\hline Duffy et al. 1998 & Number of twin pairs & 416 & 205 & 339 & 182 & 437 & - & 253 & 55 \\
\hline Kirk et al. 2000 & Number of twin pairs & 868 & 455 & 372 & 183 & 357 & 731 & 590 & 108 \\
\hline Levy et al. 1996 *** & Number of twin pairs & 548 & 498 & 308 & 336 & 539 & - & 437 & 202 \\
\hline Wright et al. 2001 & Number of twin pairs & 117 & 109 & 70 & 63 & 138 & - & 120 & 66 \\
\hline \multirow[t]{7}{*}{ Combined Sample } & Number of twin pairs & 1949 & 1267 & 1089 & 764 & 1466 & 731 & 1400 & 428 \\
\hline & Mean YOB (range) & $\begin{array}{r}1966 \\
(1893\end{array}$ & $\begin{array}{r}1970 \\
(1909\end{array}$ & $\begin{array}{r}1966 \\
\text { (1901 }\end{array}$ & $\begin{array}{r}1971 \\
(1949\end{array}$ & $\begin{array}{r}1969 \\
(1906\end{array}$ & $\begin{array}{r}1962 \\
\text { (1933 }\end{array}$ & $\begin{array}{r}1968 \\
\text { (1938 }\end{array}$ & $\begin{array}{r}1974 \\
(1917\end{array}$ \\
\hline & & $-1991)$ & 1987) & $-1988)$ & $-1988)$ & $-1992)$ & $-1972)$ & $-1987)$ & $-1987)$ \\
\hline & $\begin{array}{l}\% \text { of pairs where } \\
\text { handedness of } 1 \text { twin } \\
\text { is unknown }\end{array}$ & 21.5 & 22.7 & 16.1 & 15.6 & 18.6 & 100 & 18.6 & 13.4 \\
\hline & $\begin{array}{l}\% \text { of left handed } \\
\text { discordant twin } \\
\text { pairs (RL/LR) }\end{array}$ & $\begin{array}{l}20.1 \\
21.0\end{array}$ & $\begin{array}{l}22.4 \\
21.5\end{array}$ & $\begin{array}{l}19.6 \\
21.6\end{array}$ & $\begin{array}{l}23.0 \\
25.0\end{array}$ & $\begin{array}{l}20.1 \\
22.9\end{array}$ & - & $\begin{array}{l}22.3 \\
21.4\end{array}$ & $\begin{array}{r}20.5 \\
18.8\end{array}$ \\
\hline & $\begin{array}{l}\% \text { of left handed } \\
\text { concordant twin } \\
\text { pairs (LL) }\end{array}$ & $\begin{array}{l}2.0 \\
2.6\end{array}$ & $\begin{array}{l}2.9 \\
5.0\end{array}$ & $\begin{array}{l}2.6 \\
2.3\end{array}$ & $\begin{array}{l}2.2 \\
2.7\end{array}$ & $\begin{array}{l}2.2 \\
3.5\end{array}$ & - & $\begin{array}{l}2.5 \\
3.5\end{array}$ & $\begin{array}{l}1.1 \\
2.7\end{array}$ \\
\hline & $\begin{array}{l}\text { Prevalence of left } \\
\text { handedness }\end{array}$ & $\begin{array}{l}12.4 \\
13.3\end{array}$ & $\begin{array}{l}13.8 \\
15.5\end{array}$ & $\begin{array}{l}12.2 \\
12.8\end{array}$ & $\begin{array}{l}13.7 \\
15.0\end{array}$ & $\begin{array}{l}12.6 \\
15.3\end{array}$ & $\begin{array}{l}12.2 \\
13.5\end{array}$ & $\begin{array}{l}13.5 \\
14.1\end{array}$ & $\begin{array}{l}11.4 \\
12.6\end{array}$ \\
\hline
\end{tabular}

Note: ${ }^{*}$ DZOS $=$ DZ Opposite sex twins.

** The DZ Single twins ( $56.6 \%$ female) resulted from individual attrition of one twin in a pair. As the data are anonymous and participants were not asked the sex of their co-twin it is impossible to tell if they were from a same-sex or opposite sex pair. Data from these twins were included in the univariate genetic analyses but not in any other analyses.

*** For further information regarding this ongoing study refer to Hay et al., (2002) and Rooney, et al., (2003).

for this task. Of the 1148 individuals for whom data were available $98.4 \%$ chose to perform the task with their writing hand, and $95.9 \%$ with their throwing hand suggesting that the rate of error in the questionnaire data was low.

\section{Placentation}

Placentation was used as an indicator of chorionicity and was assessed in all studies by asking, How many placentas (afterbirths) were there at birth? With participants endorsing one of four responses: single, 2 joined, 2 separate, or don't know. Due to the small number (4\%) of MZ participants who answered 2 fused the 2 separate and 2 fused categories were combined to form a single DC group in order to avoid numerical difficulties. Thus, placentation was treated as a nominal variable with two levels: MC and DC. Although no objective placentation diagnoses were available to allow validation of retrospectively reported placentation the proportion of MZ twins who were reported to be MC (77\%) was similar to that reported in the literature (Bulmer, 1970; Derom et al., 1995; Duffy, 1993). The percentage of MZ twins of known placentation and the proportion of these twins who are monochorionic and dichorionic are given in Table 2. The validity of self-reported placentation was assessed by comparing parental- and self-reported placentation for the 94 pairs of twins from the Asthma study (Duffy, 1993) for whom parental and self-reports were available, yielding a kappa coefficient of .92 .

\section{Statistical Analysis}

Our analyses are conducted within the framework of the Multi-Factorial Thresholds model which posits a continuous normally distributed liability for laterality on which thresholds are imposed which define the prevalence of different definitions of handedness. The thresholds may be influenced by various factors, including age, sex, zygosity and placentation. These factors can be estimated as fixed effects in a threshold model, as part of the Maximum Likelihood Estimation procedure implemented in Mx (1.52), which we use for these analyses (Neale, 2000). The model also assumes that the joint distribution of liabilities for a pair of twins (or siblings) is bi-variate normal, and the correlation between liabilities can be estimated as a random effect, while estimating the fixed effects in the thresholds. The procedure is readily extended to multiple groups so that we can test hypotheses about equality of thresholds or correlation between studies, or zygosity and placentation groups.

Although the frequency of left-handedness is often reported to be lower in older samples, the effect of age on handedness is related to the year of birth and cultural and educational pressures rather than maturation or mortality (Hicks et al., 1994). Thus, Age (defined as year of birth rather than age at data collection) was used as a moderator variable. Since there was a wide range of ages (the oldest participants were born in 1893 and the youngest in 1992), to avoid numerical problems, Age was re-scaled, by subtracting 
1893 from the year of birth and dividing the result by 10 . This produced a continuous definition variable ranging between 0 and 9.9 that was used to control for any linear or quadratic effects of age on handedness.

\section{Testing the Homogeneity of Data from the Four Studies}

Since the data being analyzed were collected in four different studies, it was first necessary to test the equality of thresholds and correlations across the four studies. This was done separately for each zygosity group. Thus, for example, the data from the $\mathrm{MZ}$ female twins were modelled as a four-group data set (with participants from each of the four studies forming a separate group). The thresholds of first and second-born twins were allowed to vary. Age (linear and quadratic) and Sex regressions were estimated for thresholds across groups to correct for the effects of these variables. The fit of the saturated model in which both thresholds and correlations were allowed to vary between groups was compared to a model in which the thresholds were allowed to vary with birth order, but constrained to be equal across groups. The fit of this model was then subsequently compared to the fit of a model in which the co-twin correlations were constrained to be equal across groups. The fit of each sub-model was compared to the one within which it was nested by a likelihood ratio chi-square test (Neale \& Cardon, 1992). The difference in minus two-log likelihood (-2LL) between the models was compared to the critical value of the chisquare distribution for the difference in degrees of freedom. A non-significant $\chi^{2}$ indicates no depreciation in fit between the reduced model and the more complicated model within which it was nested.

\section{Examining the Effects of Chorionicity}

To determine whether the prevalence of left-handedness and magnitude of co-twin correlations differed for MZ MC and MZ DC twins, the data from MZ twins of known placentation was modelled as a two group (MC/DC) data set. Age (linear and quadratic) and Sex regressions were estimated for thresholds across groups to correct for the effects of these variables. The fit of the saturated model in which both thresholds and correlations were allowed to vary between groups was compared to a model in which the prevalences of left-handedness in MZ MC and MZ DC twins were constrained to be equal. This model was then compared with one in which the co-twin correlations of MZ MC and MZ DC twins were constrained to be equal.

\section{Hypotheses Regarding the Effects of Birth Order, Zygosity, and Multiple birth}

A series of models was tested using the full sample of twin and sibling data to assess the effects of birth order, zygosity and multiple birth. The contrasts used to test these hypotheses are given in Table 3 below. In the saturated model the thresholds of the first and second-born twins and the two siblings were allowed to vary, the co-twin, twin-sibling, and sibling-sibling correlations were also allowed to vary. Thus, each of the five zygosity groups had four thresholds (one for each of the two twins and two siblings), and six correlations (the co-twin correlation, four sib-twin correlations and a sib-sib correlation).

The first sub model $\left(\mathrm{H}_{1 \mathrm{~T}}\right)$ tested for the presence of birth order effects by equating the thresholds of the first and second-born twins within the same sex zygosity groups. The second sub model $\left(\mathrm{H}_{2 \mathrm{~T}}\right)$ tested for homogeneity of thresholds between $\mathrm{MZ}$ and $\mathrm{DZ}$ twin within like-sex twin pairs by

Table 3

Contrasts Used to Test Differences about Thresholds in the Analysis of Individual Observations for Twin Pairs and Siblings Twin 1 Refers to the First-born Twin, Twin 2 to the Second-born Twin

\begin{tabular}{|c|c|c|c|c|c|c|c|}
\hline & & $\begin{array}{c}\mathrm{H}_{0 \mathrm{~T}} \\
\text { Saturated Model }\end{array}$ & $\begin{array}{c}\mathrm{H}_{1 \mathrm{~T}} \\
\text { Birth Order }\end{array}$ & $\begin{array}{c}\mathrm{H}_{2 \mathrm{~T}} \\
\text { Same } \\
\text { sex twins }\end{array}$ & $\begin{array}{c}\mathrm{H}_{3 \mathrm{~T}} \\
\text { Same \& Opposite } \\
\text { sex twins }\end{array}$ & $\begin{array}{c}\mathrm{H}_{4 \mathrm{~T}} \\
\text { Siblings }\end{array}$ & $\begin{array}{c}\mathrm{H}_{5 \mathrm{~T}} \\
\text { Twins \& } \\
\text { Siblings }\end{array}$ \\
\hline MZF & $\begin{array}{l}\text { Twin } 1 \\
\text { Twin } 2 \\
\text { Sibling } 1 \\
\text { Sibling } 2\end{array}$ & $\begin{array}{l}1 \\
2 \\
3 \\
4\end{array}$ & $\begin{array}{l}1 \\
1 \\
2 \\
3\end{array}$ & $\begin{array}{l}1 \\
1 \\
2 \\
3\end{array}$ & $\begin{array}{l}1 \\
1 \\
2 \\
3\end{array}$ & $\begin{array}{l}1 \\
1 \\
2 \\
2\end{array}$ & $\begin{array}{l}1 \\
1 \\
1 \\
1\end{array}$ \\
\hline MZM & $\begin{array}{l}\text { Twin } 1 \\
\text { Twin } 2 \\
\text { Sibling } 1 \\
\text { Sibling } 2\end{array}$ & $\begin{array}{l}5 \\
6 \\
7 \\
8\end{array}$ & $\begin{array}{l}4 \\
4 \\
5 \\
6\end{array}$ & $\begin{array}{l}4 \\
4 \\
5 \\
6\end{array}$ & $\begin{array}{l}1 \\
1 \\
4 \\
5\end{array}$ & $\begin{array}{l}1 \\
1 \\
2 \\
2\end{array}$ & $\begin{array}{l}1 \\
1 \\
1 \\
1\end{array}$ \\
\hline DZF & $\begin{array}{l}\text { Twin } 1 \\
\text { Twin } 2 \\
\text { Sibling } 1 \\
\text { Sibling } 2\end{array}$ & $\begin{array}{r}9 \\
10 \\
11 \\
12\end{array}$ & $\begin{array}{l}7 \\
7 \\
8 \\
9\end{array}$ & $\begin{array}{l}1 \\
1 \\
7 \\
8\end{array}$ & $\begin{array}{l}1 \\
1 \\
6 \\
7\end{array}$ & $\begin{array}{l}1 \\
1 \\
2 \\
2\end{array}$ & $\begin{array}{l}1 \\
1 \\
1 \\
1\end{array}$ \\
\hline DZM & $\begin{array}{l}\text { Twin } 1 \\
\text { Twin } 2 \\
\text { Sibling } 1 \\
\text { Sibling } 2\end{array}$ & $\begin{array}{l}13 \\
14 \\
15 \\
16\end{array}$ & $\begin{array}{l}10 \\
10 \\
11 \\
12\end{array}$ & $\begin{array}{r}4 \\
4 \\
9 \\
10\end{array}$ & $\begin{array}{l}1 \\
1 \\
8 \\
9\end{array}$ & $\begin{array}{l}1 \\
1 \\
2 \\
2\end{array}$ & $\begin{array}{l}1 \\
1 \\
1 \\
1\end{array}$ \\
\hline DZOS & $\begin{array}{l}\text { Twin } 1 \\
\text { Twin } 2 \\
\text { Sibling } 1 \\
\text { Sibling } 2\end{array}$ & $\begin{array}{l}17 \\
18 \\
19 \\
20\end{array}$ & $\begin{array}{l}13 \\
14 \\
15 \\
16\end{array}$ & $\begin{array}{l}11 \\
12 \\
13 \\
14\end{array}$ & $\begin{array}{r}1 \\
1 \\
10 \\
11\end{array}$ & $\begin{array}{l}1 \\
1 \\
2 \\
2\end{array}$ & $\begin{array}{l}1 \\
1 \\
1 \\
1\end{array}$ \\
\hline
\end{tabular}


constraining the thresholds of same sex MZ and DZ twins to be equal. Since a deviation had been estimated to equate the sexes, a contrast between male and female thresholds would have been redundant. Thus, $\mathrm{H}_{3 \mathrm{~T}}$ equated the thresholds of all $\mathrm{MZ}$ and DZ twins thereby testing for homogeneity of thresholds across zygosity groups. In $\mathrm{H}_{4 \mathrm{~T}}$ the siblings' thresholds were equated to check homogeneity of data across zygosity groups and allow the twins' thresholds to be compared with those of their siblings in $\mathrm{H}_{5 \mathrm{~T}}$. The significance of sex and age (linear and quadratic) effects were tested in $\mathrm{H}_{6 \mathrm{~T}}$, $\mathrm{H}_{7 \mathrm{~T}}$ and $\mathrm{H}_{8 \mathrm{~T}}$ where effects of dropping, one at a time, the regression coefficients correcting for each of these effects was examined. Regression coefficients were retained in the model if their removal resulted in a significant loss of fit.

A similar process was used to test hypotheses concerning correlations shown in Table 4 below. The first sub model $\left(\mathrm{H}_{1 \mathrm{C}}\right)$ tested for differences in the correlations of $\mathrm{MZ}$ male and female twins. The correlations of DZ like-sex twin pairs were constrained to be equal in the second sub model $\left(\mathrm{H}_{2 \mathrm{C}}\right)$. $\mathrm{H}_{3 \mathrm{C}}$ equated the correlations of opposite-sex and same sex twin pairs, thereby testing whether sharing the uterine environment with a member of the opposite sex influences handedness per se. $\mathrm{H}_{4 \mathrm{C}}$ equated the sibling-sibling and sibling-twin correlations. To determine whether there was any special DZ twin environment acting on handedness the DZ co-twin and the sibling-twin correlations were equated in $\mathrm{H}_{5 \mathrm{C}}$. These combined DZ co-twin and sibling-twin correlations were then equated with the $\mathrm{MZ}$ co-twin correlation in $\mathrm{H}_{6 \mathrm{C}}$ to determine whether handedness was influenced by genetic factors. Finally, $\mathrm{H}_{7 \mathrm{C}}$ set all correlations to zero, thereby testing for familial aggregation.

\section{Univariate Genetic Modelling}

Univariate genetic modelling was conducted to further investigate the source of familial aggregation in handedness. Structural equation modelling (using $\mathrm{Mx}$ ) was employed to estimate the proportion of phenotypic variance arising from additive (A) and non-additive (dominant D) genetic sources and shared (C) and non-shared (E) environmental influences. As our twin data come from $\mathrm{MZ}$ and $\mathrm{DZ}$ twins raised together the effects of $\mathrm{C}$ and $\mathrm{D}$ are confounded and can not be estimated together. ACE models were fitted to the data, as the $\mathrm{MZ}$ correlations were less than twice that of the DZ correlations. Subsequent sub-models tested the effect of dropping A, C or both A and C parameters on the fit $\left(\Delta \chi^{2}\right)$ and parsimony of the model as measured by Akaike's Information Criterion (AIC).

\section{$\overline{\text { Results }}$ \\ Homogeneity of Data from the Four Studies}

For the throwing hand measure, in the MZ female and DZ opposite sex zygosity groups there was significant heterogeneity between studies in the proportion of left-handers (Table 5). However, while these differences were formally significant, they are substantively trivial so we proceeded ignoring the modest evidence for heterogeneity. There were no other significant differences in either thresholds or correlations between the participants of the four different studies so data from the four studies were pooled within zygosity groups in subsequent analyses.

\section{Examining the Effects of Chorionicity}

Significant heterogeneity was observed between the thresholds of the MC and DC MZ twins for both the writing and throwing hand measures (Table 5). These differences were driven by the low rate of left-handedness in the DC secondborn twins. The prevalences of left-handedness (derived from age and sex corrected thresholds), for first and second-born MC twins were, 15.2 and $15.5 \%$ on the writing hand measure and 16.3 and $16.1 \%$ on the throwing hand measure, while the equivalent prevalences in the DC group were $14.5,10.3,17.2$ and $10.9 \%$. Taking into consideration the homogeneity of MZ MC and MZ DC correlations, and the size of the DC placentation group it is likely that this effect was due to sampling, so data from these groups were pooled for further analysis.

\section{Hypotheses Regarding the Effects of Birth Order, Zygosity, and Multiple Birth \\ Hypotheses Regarding Thresholds}

First-born twins were no more likely to be left-handed than second-born twins (Table 6) and the prevalence of left-handedness did not differ between MZ and DZ twins for either hand used for writing or hand used for throwing. Similarly,

\section{Table 4}

Contrasts used to Test Differences about Correlations in the Analysis of Individual Observations for Twin Pairs and Siblings

\begin{tabular}{|c|c|c|c|c|c|c|c|c|c|}
\hline & Correlation & $\mathrm{H}_{0 \mathrm{C}}$ & $\mathrm{H}_{1 \mathrm{C}}$ & $\mathrm{H}_{2 \mathrm{C}}$ & $\mathrm{H}_{3 \mathrm{C}}$ & $\mathrm{H}_{4 \mathrm{C}}$ & $\mathrm{H}_{5 \mathrm{C}}$ & $\mathrm{H}_{6 \mathrm{C}}$ & $\mathrm{H}_{7 \mathrm{C}}$ \\
\hline \multirow[t]{2}{*}{ MZF } & Co-Twin & 1 & 1 & 1 & 1 & 1 & 1 & 1 & 0 \\
\hline & Sib-Sib * & $2-6$ & $2-6$ & $2-6$ & $2-6$ & 2 & 2 & 1 & 0 \\
\hline \multirow[t]{2}{*}{ MZM } & Co-Twin & 7 & 1 & 1 & 1 & 1 & 1 & 1 & 0 \\
\hline & Sib-Sib & $8-12$, & $7-11$ & $7-11$ & $7-11$ & 2 & 2 & 1 & 0 \\
\hline \multirow[t]{2}{*}{ DZF } & Co-Twin & 13 & 12 & 12 & 12 & 3 & 2 & 1 & 0 \\
\hline & Sib-Sib & 14-18 & $13-17$ & $13-17$ & $13-17$ & 2 & 2 & 1 & 0 \\
\hline \multirow[t]{2}{*}{ DZM } & Co-Twin & 19 & 18 & 12 & 12 & 3 & 2 & 1 & 0 \\
\hline & Sib-Sib & $20-24$ & 19-23 & 18-22 & $18-22$ & 2 & 2 & 1 & 0 \\
\hline \multirow[t]{2}{*}{ DZOS } & Co-Twin & 25 & 24 & 23 & 12 & 3 & 2 & 1 & 0 \\
\hline & Sib-Sib & $26-30$ & $25-29$ & 24-28 & $23-27$ & 2 & 2 & 1 & 0 \\
\hline
\end{tabular}

Note: * Sib-Sib correlation refers to both the twin-sibling correlations (of which there are four) and the non-twin sibling-sibling correlation. 
there were no differences in the prevalence of left-handedness among the twins' singleton siblings or between the twins and their siblings.

\section{Covariates: Age and Sex}

As indicated in Figure 1 significant age effects were found on both measures $\left(\mathrm{H}_{6}\right.$ and $\left.\mathrm{H}_{7}\right)$. There were significant linear and quadratic effects of age on the writing-hand measure (regression $\beta$ from $\mathrm{H}_{0},=.03$, and -.14 ), while a linear, but not a quadratic effect of age, was found on throwing-hand, with the threshold moving .05 units to the right for every 15 years decrease in year of birth (regression $\beta$ from $\mathrm{H}_{0}$, $=.05$ ). Consistent with the majority of the published literature, males were more likely to be left-handed than females (writing-hand, 14.0 vs. $11.9 \%$, throwing-hand, 15.5 vs. 13.2 $\%)$. A significant sex effect $\left(\mathrm{H}_{9 \mathrm{~T}}\right)$ was also seen for both measures, the male threshold was displaced .16 units to the right of the female threshold on the writing hand measure and .11 units on the throwing hand measure (regression $\beta$ from $\mathrm{H}_{0}$, writing-hand $=.16$, throwing-hand $=.11$ ).

\section{Hypotheses Concerning Correlations}

For the writing measure, the correlations of male and female $\mathrm{MZ}$ twins did not differ. However, there was evidence of minor heterogeneity between the correlations of $\mathrm{MZ}$ male and female twins for the throwing hand measure. While this result suggests that the heritability of handedness for throwing may be greater for one sex than the other we do not have sufficient power to test this hypothesis with the present sample. There were no significant differences between the correlations of male and female DZ twins or between likeand opposite-sex DZ twins on either measure (summarized in Table 6). The twin-sibling and sibling-sibling correlations did not differ and constraining the DZ co-twin, twin-sibling and sibling-sibling correlations to be equal did not significantly alter the fit of the model. Thus, there was no evidence to suggest that handedness is influenced by the shared preand post-natal environments of twins. Which suggests that intra-uterine crowding (if present) does not significantly alter handedness as measured by writing or throwing. There was no difference between the $\mathrm{MZ}$ and $\mathrm{DZ}$ co-twin correlations

\section{Table 5}

Differences in Log Likelihood $\Delta \chi^{2}$ for Tests Concerning the Heterogeneity of Data across Studies and MZ Chorionicity Groups

\begin{tabular}{lcccc}
\hline \multirow{2}{*}{$\begin{array}{l}\text { Tests for the equality of: } \\
\text { Zygosity Group }\end{array}$} & \multicolumn{2}{c}{ Thresholds $(d f 6)$} & \multicolumn{2}{c}{ Correlations (3) } \\
\hline MZ Females & Writing Hand & Throwing Hand & Writing Hand & Throwing Hand \\
MZ Males & 6.57 & $16.10^{*}$ & 1.73 & .70 \\
DZ Females & 8.22 & 9.82 & .71 & 3.31 \\
DZ Males & 4.73 & 3.47 & 4.88 & 3.87 \\
DZ Opposite Sex & 7.81 & 8.68 & 5.03 & 5.77 \\
\hline Tests for the equality of: & 8.64 & $12.59^{*}$ & Correlations (1) \\
Chorionicity Groups & \multicolumn{2}{c}{ Thresholds $(d f 2)$} & Writing Hand & Throwing Hand \\
\hline MZ MC vs MZ DC & Writing Hand & Throwing Hand & 1.19 & .07 \\
\hline
\end{tabular}

Note: ${ }^{*} p<.05,{ }^{* *} p<.01,{ }^{* * *} p<.001$

Table 6

Differences in Log Likelihood $\Delta \chi^{2}$ for Hypotheses Regarding the Effects of Birth Order, Zygosity, and Multiple Birth on Threshold and Correlations on the Writing Hand and Throwing Hand Measures

\begin{tabular}{|c|c|c|c|}
\hline Hypothesis & Df & $\Delta \chi^{2}$ Writing hand & $\Delta \chi^{2}$ Throwing hand \\
\hline \multicolumn{4}{|l|}{ Thresholds } \\
\hline $1 \mathrm{~T}$ - First \& second-born twins equal & 3 & 2.31 & 3.95 \\
\hline $2 \mathrm{~T}$ - Like-sex twin pairs equal & 2 & 1.25 & .97 \\
\hline 3T - MZ \& DZ twins equal & 3 & 6.31 & 1.07 \\
\hline $4 \mathrm{~T}$ - All Siblings equal & 9 & 7.25 & 5.55 \\
\hline 5T — Twins \& siblings equal & 1 & .57 & 3.13 \\
\hline $6 \mathrm{~T}-\mathrm{No}$ linear age regression & 1 & $8.82^{* *}$ & $11.69^{* * *}$ \\
\hline $7 \mathrm{~T}$ - No quadratic age regression & 1 & $8.85^{* *}$ & .61 \\
\hline $8 \mathrm{~T}-$ No sex difference & 1 & $15.18^{* * *}$ & $12.43^{* * *}$ \\
\hline \multicolumn{4}{|l|}{ Correlations } \\
\hline $1 \mathrm{C}-\mathrm{MZF} \& \mathrm{MZM}$ twins equal & 1 & .25 & $4.62^{*}$ \\
\hline 2C - DZF \& DZM twins equal & 1 & 1.49 & .09 \\
\hline 3C - DZF, DZM \& DZOS twins equal & 1 & .04 & 2.63 \\
\hline $4 \mathrm{C}-$ Siblings equal & 24 & 23.71 & 25.80 \\
\hline 5C - DZF, DZM, DZOS twins \& siblings equal & 1 & .20 & .20 \\
\hline $6 \mathrm{C}-\mathrm{MZ}$ twins with $\mathrm{DZ}$ twins and siblings equal & 1 & .07 & $4.54^{*}$ \\
\hline 7C - Familial Aggregation & 1 & $29.67^{* * *}$ & $60.80^{* * *}$ \\
\hline
\end{tabular}




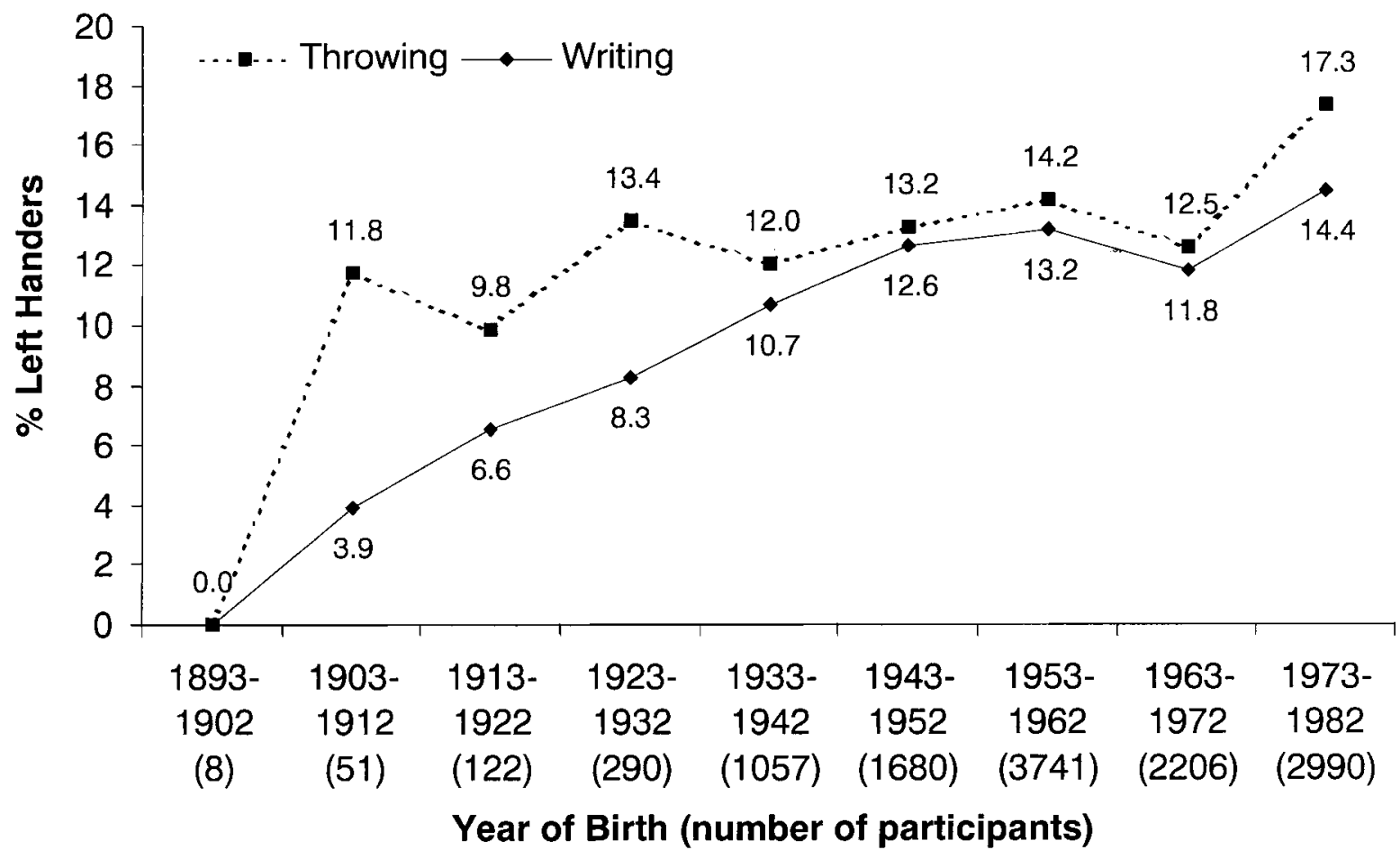

FIGURE 1

Percentage of left handedness for throwing and writing in the combined sample by year of birth.

$\left(\mathrm{H}_{6 \mathrm{C}}\right)$, on the writing measure. Correlations and $95 \%$ confidence intervals from $\mathrm{H}_{5 \mathrm{C}}: \mathrm{MZ}=.15(.14-.17) \mathrm{DZ}=.13$ (.12-.15). This suggests that the significant familial aggregation on this variable $\left(\mathrm{H}_{7 \mathrm{C}}\right)$ may be best explained through the influences of shared environment. However, for the throwing-hand measure, constraining the $\mathrm{MZ}$ and $\mathrm{DZ}$ co-twin correlations to be equal resulted in a decrease in the fit of the model (significant at $p=.05$ ), suggesting that the familial aggregation on this variable may be due to genetic effects. Correlations and $95 \%$ confidence intervals from $\mathrm{H}_{5 \mathrm{C}}$ : $\mathrm{MZ}=.26(.19-.31) \mathrm{DZ}=.15(.13-.16)$.

\section{Univariate Modelling}

The results of the model fitting and standardized variance components are presented in Table 7 . In both the writing hand and throwing hand analyses, either the additive genetic or common environmental component could be dropped from the model. In the most parsimonious model of variation in writing hand (AIC -1.66) common environmental factors explained $12.2 \%$ of the variance in writing hand (95\% Confidence Intervals 6.5-17.9\%) with unique environmental factors explaining the remaining variance $87.8 \%$ (CI: 82.1-93.5\%). An AE model provided the best explanation of variation in writing hand (AIC -1.61) with additive genetic factors explaining $27.3 \%$ of the variance in writing hand (95\% Confidence Intervals 20.0-34.5\%) with unique environmental factors explaining the remaining variance $72.7 \%$ (CI: $65.5-80.0 \%$ ). These results indicate the presence of a small but significant genetic influence on hand used for throwing and a slightly smaller common environmental influence on writing hand.

\section{Discussion}

Does the Experience of Twinning Affect Handedness?

Previous findings of an increased prevalence of left-handedness in twins as compared to singletons, and birth order effects in twins have been interpreted as reflecting increased rates of pathogenic handedness in twins (Christian et al.,

Table 7

Results of Fitting Genetic and Environmental Models to Raw Data Pooled by Study, Sex, Zygosity and Chorionicity. Models Shown are Tested Against an ACE Model

\begin{tabular}{|c|c|c|c|c|c|}
\hline \multirow[t]{2}{*}{ Model } & \multirow[t]{2}{*}{$d f$} & \multicolumn{2}{|c|}{ Writing hand } & \multicolumn{2}{|c|}{ Throwing hand } \\
\hline & & $\Delta \chi^{2}$ & AIC & $\Delta \chi^{2}$ & AIC \\
\hline$\overline{\mathrm{AE}}$ & 1 & .77 & -1.23 & .39 & -1.61 \\
\hline CE & 1 & .34 & -1.66 & 3.53 & 1.53 \\
\hline $\mathrm{E}$ & 1 & $17.96^{* * *}$ & 15.96 & $53.40^{* * *}$ & 51.40 \\
\hline
\end{tabular}


1979; James \& Orlebeke, in press; Orlebeke et al., 1996; Sicotte et al., 1999). However, the present study found no evidence to support this theory in either hand used for writing or throwing. Second-born DC twins were less likely to be left-handed than their co-twins. However, this birth order effect resulted from a decrease in left-handedness in the second-born twins rather than an increase in left-handedness in the first-born. Given the small number of DC twins, the limitations associated with the placentation data (described below), and the lack of any other birth order effects it seems likely that this result may be not be a true effect. No other differences were found in the prevalence of left-handedness between first and second-born twins, which suggests that exposure to pathogenic influences did not differ between cotwins. Similarly, there were no significant differences between the prevalence of left-handedness among twins and siblings. Thus, the distribution of handedness in our twin sample did not differ significantly from that seen in a sample of singletons as seen in other contemporary twin studies (Sicotte et al., 1999).

The similarity between DZ co-twin and twin-sibling covariances suggests that intra-uterine crowding does not influence the handedness of twins. This finding also suggests that the influence of a DZ twin on their co-twins handedness is no greater than the influence of a sibling, suggesting that the effects of peri-natal influences such as face to face play, do not differ depending on whether the playmate is a co-twin or a sibling. Taken together these results suggest that the level of pathogenic handedness in this sample was fairly low, as the second-born twin is more likely to experience cesarean section, breech presentations, instrumental deliveries and higher levels of birth stress than the first, and twins are more likely to experience these events than their singleton siblings (Voss, 1996). Although studies have reported higher rates of left-handedness in twins than siblings the rates of left-handedness in the present sample $(-13 \%)$ are very similar to those seen in contemporary twin and singleton populations. It is possible that a special twin environment effect may have been operating in some of the earlier samples reported in previous studies, decreasing the influence of social pressures that are no longer operating in Australian communities.

\section{Does the Process of MZ Twinning Affect Handedness?}

Anecdotal reports and case studies leave us in no doubt that some $\mathrm{MZ}$ twin pairs do display mirrored features. In one of the few objective studies of mirror imaged facial characteristics Townsend and colleagues (Brown et al., 1987; Townsend et al., 1986), compared stereophotogrammetric images of cotwins' faces (using root mean square analysis of distances between homologous points), before and after one twin's image had been flipped over to determine whether the twins showed mirrored features. Although they found individual cases of mirror imaging, they concluded there was no indication of a general trend towards mirroring in $\mathrm{MZ}$ twins (Brown et al., 1987; Townsend et al., 1986), or indication that mirroring, "arises as a special consequence of the twinning process rather than by chance alone" (Townsend et al., 1986, p 89). The chorionicity of these mirrored twins (if known) was not reported, and the extent of mirroring in
$\mathrm{DZ}$ twins (if measured) was not discussed, thus it is difficult to know whether mirror imaging truly is influenced by nature and timing of the $\mathrm{MZ}$ twining event as the mirror imaging theory predicts.

Mirror imaging if present, would act to increase the prevalence of left-handedness and decrease the correlation in $\mathrm{MC}$ twins when compared to DC twins (although it should be noted that the extent to which this occurs would depend on the relative strength of the genetic and mirroring effects). However, this is not the case in the present sample. The present study found no influence of placentation on either the prevalence of left-handedness (as assessed by either writing or throwing) or the covariance in handedness between co-twins. Although there was a difference between the thresholds of MC and DC twins, this difference was not due to an increase in left-handedness in the MC twins as predicted by the theory of mirror imaging, instead, it reflected a decrease in left-handedness the second-born DC twins as described above. Thus, while it is possible that some MZ twins in this sample may be mirror imaged, like other contemporary studies examining handedness in twins (Carlier et al., 1996; Derom et al., 1996), the present study found no evidence to suggest mirror imaging is having a major effect on the handedness of $M Z$ twin pairs.

\section{Genetic Influences on Handedness}

No differences were found between the co-twin correlations of $\mathrm{MZ}$ and $\mathrm{DZ}$ twins on the writing-hand measure, which suggests that the significant familial aggregation found on hand used for writing is due to common environmental rather than genetic factors. However, the MZ co-twin correlation was significantly higher than the DZ co-twin correlation on the throwing-hand measure, suggesting that the familial aggregation on hand used for throwing is genetic in nature.

While writing-hand is highly correlated with throwinghand $(r=.94)$ the influence of social/cultural pressures on the hand used for writing is stronger than those on the hand used for throwing. Although we have controlled for the effects of observable variables such as year of birth and sex, we are unable to control for other more subtle influences that may affect the hand one uses for writing thereby obscuring the effect of genetic influences on this variable. It is possible that throwing may be less influenced by these factors, as it is a skill that most individuals develop in early childhood (although accuracy may take years to develop) while most children receive formal instruction in how to write at a somewhat later age. Similarly, throwing is generally a self-instructed task, while most individuals receive instruction in writing from an adult, as one of a group of age peers. It is possible that a range of heterogeneous environmental confounds might be acting to increase the amount of variance due to common environmental factors on the writing-hand measure thereby obscuring a possible genetic effect. Similarly, it is possible that the relaxation of social pressures may have resulted in differences in heritability between older and younger birth cohorts. However, given that handedness is a dichotomous variable of low frequency we have insufficient power (despite the size of our sample) to test this hypothesis. These results suggest that the magnitude 
of genetic effects may differ between handedness measures and that multivariate analyses which partition the co-variance between handedness measures into genetic and environmental sources may provide valuable information about the sources and structure underlying the covariation of these and other handedness measures.

\section{Limitations}

The data were collected using questionnaire methods, which may actually be an advantage when studying handedness; if writing hand is used as the criterion, the respondent is provided with a visual cue while answering the question. The correlation between parental and self-reported handedness indicated that parental reports could be considered reliable. In addition the concordance between writing hand and the hand chosen by adolescent twins to perform a task scored on speed and accuracy (in which a monetary reward was given for performance) suggests that the self-report of handedness was accurate.

However, the accuracy of the placentation data may be less reliable. Parental reports of placentation information may be error prone, depending firstly on accurate investigation and diagnosis of placentation, and secondly on accurate memory for this information. Self-reported placentation introduces a third source of error as it depends on the original diagnosis of placentation being passed from parent to offspring. Although the prevalence of MC placentation in our study is similar to that reported in the literature from examination of placentae in a large series of twin births (Bulmer, 1970; Derom et al., 1995), there is no way to assess the accuracy of this data.

Accuracy problems similar to those seen in the placentation data may be found in the birth order data. Unfortunately there were no objective data available to verify the reported birth order, although one would imagine that parents are more likely to be interested in (and thus more likely to correctly remember and recall) the order in which their twins were born, than in the number of placentas present in the birth.

In conclusion the present study found no evidence that handedness is influence by either the experience of twinning per se or the timing of the twinning event in $\mathrm{MZ}$ twins. Thus, in the largest study of twins and their siblings to date, there was no indication of either a special twin environment or of mirror imaging. The rates of left-handedness in the twins were comparable to those seen in their singleton siblings, and those reported in the literature. Univariate genetic analyses revealed common environmental factors to be the most parsimonious explanation of familial aggregation when writing-hand is used as an indicator of handedness, while additive genetic influences provide a better interpretation of the throwing hand data. In a future paper we shall examine the genetic and environmental bases of the co-variation between different handedness measures.

\section{Acknowledgments}

The data analyzed in the present study were collected with the support of the Human Frontier Science Program (Grant Number RG0154/1998-b), the US National Institute of Mental Heath (USA), the Australian National Health and
Medical Research Council (Grant Numbers 921103, 941177), the Australian Research Council (Grant Numbers A79600334, A79906588, A79801419), the Government Employees' Medical Research Fund (Australia), and a small Commonwealth AIDS Research Grant to N. G. M. The authors thank all those associated with data collection in the various studies, and the twins and their families for their participation.

\section{$\overline{\text { References }}$}

Annett, M. (1985). Left, right, hand and brain: The right shift theory. London: Lawrence Erlbaum Associates.

Annett, M. (1996). Laterality and types of dyslexia. Neuroscience and Biobehavioral Reviews, 20, 631-636.

Brown, T., Townsend, G. C., Richards, L. C., \& Travan, G. R. (1987). A study of dentofacial morphology in South Australian twins. Australian Dental Journal, 32, 81-90.

Bryden, M., Roy, E., McManus, I., \& Bulman-Fleming, M. (1997). On the genetics and measurement of human handedness. Laterality, 2, 317-336.

Bulmer, M. G. (1970). The biology of twinning in man. Oxford: Clarendon Press.

Carlier, M., Spitz, E., Vacher-Lavenu, M. C., Villeger, P., Martin, B., \& Michel, F. (1996). Manual performance and laterality in twins of known chorion type. Behavior Genetics, 26, 409-418.

Carter-Saltzman, L., Scarr-Salapatek, S., Barker, W. B., \& Katz, S. (1976). Left-handedness in twins: Incidence and patterns of performance in an adolescent sample. Behavior Genetics, $6,189-203$

Chitnis, S., Derom, C., Vlietinck, R., Derom, R., Monteiro, J., \& Gregersen, P. K. (1999). X chromosome-inactivation patterns confirm the late timing of monoamniotic-MZ twinning. American Journal of Human Genetics, 65, 570-571.

Christian, J. C., Hunter, D. S., Evans, M. M., \& Standeford, F. M. (1979). Association of handedness and birth order in monozygotic twins. Acta Geneticae Medicae et Gemellologiae, $28,67-68$.

Coren, S., \& Halpern, D. F. (1991). Left handedness: A marker for decreased survival fitness. Psychological Bulletin, 109, 90-106.

Davis, J. O., \& Phelps, J. A. (1995). Twins with schizophrenia: genes or germs. Schizophrenia Bulletin, 21, 13-18.

Derom, C., Thiery, E., Vlietinck, R., \& Loos, R. (1996). Handedness in twins according to zygosity and chorion type: A preliminary report. Behavior Genetics, 26, 407-408.

Derom, R., Derom, C., \& Vlietinck, R. (1995). Placentation. In L. Keith \& E. Papiernik \& D. M. Keith \& B. Luke (Eds.), Multiple pregnancy: Epidemiology, gestation and perinatal outcome (pp. 113-128). London: Parthenon Publishing.

Duffy, D. L. (1993). Twin studies in medical research (Letter). Lancet, 341, 1418-1419.

Duffy, D. L. (2002). SIB-PAIR: A program for simple genetic analysis (Version 0.99.9)

Duffy, D. L., Mitchell, C. A., \& Martin, N. G. (1998). Genetic and environmental risk factor for asthma: A cotwin-control study. American Journal of Respiratory and Critical Care Medicine, 157, 840-845.

Francks, C., Fisher, S., MacPhie, L., Richardson, A., Marlow, A., Stein, J., \& Monaco, A. (2002). A genomewide linkage screen 
for relative hand skill in sibling pairs. American Journal of Human Genetics, 70, 800-805.

Francks, C., DeLisi, L. E., Fisher, S. E., Laval, S. H., Rue, J. E., Stein, J. F., et al. (2003). Confirmatory evidence for linkage of relative hand skill to 2p12-q11. (Letter) American Journal of Human Genetics, 72, 499-502.

Hay, D. A ., \& Howie, P. M. (1980). Handedness and differences in birthweight of twins. Perceptual and Motor Skills, 51, 666.

Hay, D. A., McStephen, M., Levy, F., \& Pearsall-Jones, J. (2002). Recruitment and attrition in twin register studies of childhood behavior: the example of the Australian twin ADHD project. Twin Research, 5, 324-328.

Hepper, P., McCartney, G., \& Shannon, E. (1998). Lateralized behaviour in first trimester human foetuses. Neuropsychologia, 36, 521-534.

Hicks, R. A., Johnson, C., Cuevas, T., Deharo, D., et al. (1994) Do right handers live longer? An updated assessment of baseball player data. Perceptual and Motor Skills, 78I, 1243-1247.

James, W. H., \& Orlebeke, J. F. (2002). Determinants of handedness in twins. Laterality, 7, 301-307.

James, W. H., \& Orlebeke, J. F. (in press). Determinants of handedness in twins. Laterality.

Kirk, K. M., Bailey, J. M., Dunne, M. P., \& Martin, N. G. (2000). Measurement models for sexual orientation in a community twin sample. Behavior Genetics, 30, 345-356.

Levin, M. (1999). Twinning and embryonic left-right asymmetry. Laterality, 4, 197-208.

Levy, F., Hay, D., McLaughlin, M., Wood, C., \& Waldman, I. (1996). Twin-sibling differences in parental reports of ADHD, speech, reading and behavior problems. Journal of Child Psychology and Psychiatry, 37, 569-578.

McManus. (1980). Handedness in twins: A critical review. Neuropsychologia, 18, 347-355.

McManus, C. (2002). Right hand, left hand: The origins of asymmetry in brains, bodies, atoms and cultures. London: Weidenfeld \& Nicolson.

McManus, I. C. (1985). Handedness, language dominance and aphasia: A genetic model. Psychological Medicine Monographs Supplement, 8, 1-140.

Monterio, J., Derom, C., Vlientinck, R., Kohn, N., Lesser, M., \& Gregersen, P. K. (1998). Commitment to X inactivation precedes the twinning event in monochorionic MZ twins. American Journal of Human Genetics, 63, 339-346.

Neale, M. (2000). Statistical Modelling with Mx. Department of Psychiatry, Box 126 MCV, Richmond, VA 23298.

Neale, M. C. (1986). Handedness in a sample of volunteer twins. Behavior Genetics, 18, 69-79.

Neale, M. C., \& Cardon, L. R. (1992). Methodology for genetic studies of twins and families (3rd ed.). Dordrecht, the Netherlands: Kluwer Academic Publishers.

Newman, H. M. (1928). Studies of Human Twins II. Asymmetry reversal of mirror imaging in identical twins. Biological Bulletin, 55, 298-315.

Orlebeke, J. F., Knol, D. L., Koopmans, J. R., Boomsma, D. I., \& Bleker, O. P. (1996). Left-handedness in twins: Genes or environment? Cortex, 32, 479-490.

Orlebeke, J. F., van Baal, G. C. M., Boomsma, D. I., \& Neeleman, D. (1993). Birth weight in opposite sex twins as compared to same sex dizygotic twins. European Journal of Obsterics Gynaecology and Reproductive Biology, 50, 95-98.

Phillips, D. I. W., Davies, M. J., \& Robinson, J. S. (2001). Fetal growth and the fetal origins hypothesis in twins - Problems and perspectives. Twin Research, 4, 327-331.

Powls, A., Botting, N., Cooke, R. W. I., \& Marlow, N. (1996). Handedness in very-low-bithweight (VLBW) children at 12 years of age: Relation to perinatal and outcome variables. Developmental Medicine and Child Neurology, 38, 594-602.

Pujol, J., Deus, J., Losilla, J. M., \& Capdevila, A. (1999). Cerebral lateralization of language in normal left handed people studies by functional MRI. Neurology, 52, 1038-1043.

Raney, E. T. (1938). Reversed lateral dominance in identical twins. Journal of Experimental Psychology, 23, 304-312.

Reiss, M., Tymnik, G., Kögler, P., \& Kögler, W. (1999). Laterality of Hand, Foot, Eye and Ear in twins. Laterality, 4, 287-298.

Rife, D. C. (1933). Genetic studies of monozygotic twins. III. Mirror-imaging. Journal of Heredity, 24, 443-446.

Rife, D. C. (1940). Handedness, with special reference to twins. Genetics, 25, 178-186.

Roman-Goldzieher, K. (1945). Investigations of the script and writing of twins. Beihefte zur Schweizerischen Zeitschift fuer Psychologie und ihre Anwedungen, 6, 29-55.

Rooney, R., Hay, D., \& Levy, F. (2003). Small for gestational age as a predictor of behavioral and learning problems in twins. Twin Research, 6, 46-55.

Ross, D. C., Jaffe, J., Collins, R. L., Page, W., \& Robinette, D. (1999). Handedness in the NAS/NRC Twin Study. Laterality, 4, 257-264.

Sicotte, N., Woods, R., \& Mazziotta, J. (1999). Handedness in twins: a meta-analysis. Laterality, 4, 265-286.

Sommer, I., Ramsey, N., Graafmans, D., Mandl, R., Bouma, A., \& Kahn, R. (2001). Mirror-imaged language activation patterns in healthy monozygotic twins (On line Abstract). Human Brain Mapping, Abstract No.607, http://www.apnet.com/www/ journal/hbm2001/10336.html

Sommer, I. E. C., Ramsey, N. F., Bouma, A., \& Kahn, R. S. (1999). Cerebral mirror-imaging in a monozygotic twin. Lancet, 354, 1445-1446.

Townsend, G. C., Brown, T., Richards, L. C., Rogers, J. R., Pinkerton, S. K., Traven, G. R., et al. (1986). Metric analyses of the teeth and faces of South Australian twins. Acta Genticae Medicae et Gemellologiae, 35, 179-192.

Trejo, V., Derom, C., Vlietinck, R., Ollier, W., Silman, A., Ebers, G., et al. (1994). X chromosome inactivation patterns correlate with fetal-placental anatomy in monozygotic twin pairs: Implications for immune relatedness and concordance for autoimmunity. Molecular Medicine, 1, 62-70.

Van Agtmael, T., Forrest, S. M., \& Williamson, R. (2002). Parametric and non-parametric linkage analysis of several candidate regions for genes for human handedness. European Journal of Human Genetics, 10, 623-630.

Voss, D. H. (1996). Outcome. In S. A. Gall (Ed.), Multiple pregnancy and delivery (pp. 305-320). St Louis: Mosby.

Wright, M., De Geus, E., Ando, J., Luciano, M., Posthuma, D., Ono, Y., et al. (2001). Genetics of Cognition: Outline of a Collaborative Twin Study. Twin Research, 4, 48-56. 